\title{
A process-based analysis of the suitability of copula types for peak-volume flood relationships
}

\author{
J. Szolgay ${ }^{1}$, L. Gaál ${ }^{1,2}$, S. Kohnová ${ }^{1}$, K. Hlavčová ${ }^{1}$, R. Výleta ${ }^{1}$, T. Bacigál ${ }^{3}$, and G. Blöschl ${ }^{2}$ \\ ${ }^{1}$ Department of Land and Water Resources Management, Faculty of Civil Engineering, Slovak University of \\ Technology, Bratislava, Slovakia \\ ${ }^{2}$ Institute for Hydraulic and Water Resources Engineering, Vienna University of Technology, Vienna, Austria \\ ${ }^{3}$ Department of Mathematics and Descriptive Geometry, Faculty of Civil Engineering, Slovak University of \\ Technology, Bratislava, Slovakia
}

Correspondence to: J. Szolgay (jan.szolgay@stuba.sk)

Received: 17 March 2015 - Accepted: 17 March 2015 - Published: 11 June 2015

\begin{abstract}
The work aims at analyzing the bivariate relationship between flood peaks and flood volumes, with a particular focus on the type and seasonality of flood generation processes. Instead of the usual approach that deals with an analysis of the annual maxima of flood events, the current analysis includes all independent flood events in a catchment. Flood events are considered independent when they originate from distinguishably different synoptic/meteorological situations. The target region is located in the northern part of Austria, and consists of 72 small and mid-sized catchments. On the basis of the discharge measurements with a time resolution of $1 \mathrm{~h}$ from the period 1976-2007, independent flood events were identified and were assigned to one of the three following flood generation type categories: synoptic floods, flash floods and snowmelt floods. These were subsequently divided into two seasons, thereby separating predominantly rainfall-fed and snowmelt-fed floods. Nine frequently-used copula types were locally fitted to the samples of the flood type and seasonal data. Their goodness-of-fit was examined locally as well as analyzed in a regional scope. It was concluded that (i) treating flood processes separately is beneficial for the statistical analysis; (ii) suitability patterns of acceptable copula types are distinguishably different for the seasons/flood types considered, (iii) the Clayton and Joe copulas shows an unacceptable performance for all the seasons/flood types in the region; (iv) the rejection rate of the other copula types depends on the season/flood type and also on the sample size; (v) given that usually more than one statistically suitable dependence model exists, an uncertainty analysis of the design values in the engineering studies resulting from the choice of model seems unavoidable; (vi) reducing uncertainty in the choice of model could be attempted by a deeper hydrological analysis of the dependence structure between flood peaks and volumes in order to give hydrological support to the decision on model's suitability in specific regions and for typical flood generation mechanisms.
\end{abstract}

\section{Introduction}

The design of flood retention basins and other hydraulic structures where storage is involved requires the entire hydrograph or, at least, the flood volume/shape estimates related to the flood peaks. Therefore, the relationship between flood peaks and volumes is an interesting scientific research issue both from the statistical and hydrological points of view. In particular, the examination of the interplay of climatic and catchment processes in defining the probabilities of peaks and volumes is a challenging problem (Gaál et al., 2015). In engineering hydrology practice, the statistical analysis of flood peaks and volumes are often dealt with in a multivariate frequency framework. In the past, identical marginal distributions for both random variables have been used (e.g., Goel et al., 1998; Yue et al., 2002). Recently the use of copula-based multivariate models have attracted a lot of attention. Their advantage is that they permit to separate study of the marginal distributions of the components and the de- 
pendence structure between them. Numerous studies have been published on the degree of the dependence between flood peaks and volumes (e.g., Shiau, 2003; De Michele et al., 2005; Chowdhary et al., 2011; Requena et al., 2013) and how to choose he appropriate copula functions (e.g., Favre et al., 2004; Genest and Favre, 2007). Since the problem was often approached more from a purely statistical perspective, we attempted in two previous studies to better understand the hydrological factors controlling the dependence between peaks and volumes. In Gaál et al. (2012), we analyzed the ratio of both quantities based on the concept of comparative hydrology in a regional context in Austria and compared catchments with contrasting characteristics in order to understand the controls in a holistic way. The results indicated that the catchment area is not the most important control but that the climate was found to be very important through its generating the storm type together with the process attributes through antecedent soil moisture and soil characteristics.

In Gaál et al. (2015), our aim was to understand the causal factors controlling the relationship between flood peaks and volumes for the same data. The consistency of the peakvolume relationship was quantified by Spearman's rank correlation coefficient, which ranged from about 0.2 in the high alpine catchments to about 0.8 in the lowlands. The weak dependence in the high alpine catchments was due to the mix of flood types. The results also suggested that the factors controlling the dependence were mainly related to climate rather than catchment characteristics. This work, therefore, aims at analyzing the suitability of various copula-based bivariate relationships between flood peaks and flood volumes, with a particular focus on the type and seasonality of flood generation processes with the goal of going beyond the statistics alone in the choice of the copula functions. This additional information is also important as there are rarely enough data to reliably fit the copula models of peaks and volumes for large return periods, so a priori information on causal factors may prove to be essential.

\section{The study region and data}

The data set used in this paper builds on the Austrian flood data described in Gaál et al. $(2012,2015)$ and the papers referenced therein. In this paper, the runoff data observed with a time resolution of 1 hour were used from the period 19762007. There is a wide variety of flood-generation mechanisms across Austria (e.g., Merz and Blöschl, 2003), which result in complex flood peak-volume relationships (Gaál et al., 2012). In order to reduce this complexity in this firststep analysis, we decided to restrict our analysis to a geographically more limited area, namely, the Northern Lowlands region (Fig. 1). The region is located in the northern part of Austria and covers approximately $1 / 5$ of the area of the country. The 72 catchments analyzed have areas ranging from 10.6 to $444.3 \mathrm{~km}^{2}$ (median: $78.6 \mathrm{~km}^{2}$ ), while the range of their mean elevations is 342 to $888 \mathrm{~m}$ a.s.l. (median: $571 \mathrm{~m}$ a.s.l.). The area is dominated by lowland and hilly sites, with elevations ranging from about 400 to $1500 \mathrm{~m}$ a.s.l. From a climatological point of view, the western parts of the region are under the influence of air masses from the Atlantic. Since the orographic enhancement is not significant, the annual rainfall amounts (from about 500 to $1500 \mathrm{~mm}$ ) are lower than in the Alps. The mean annual precipitation in the target region shows a decreasing western-to-eastern gradient. Floods in the Northern Lowlands region may occur both during the summer and winter. The winter floods are usually induced by snowmelt and rain-on-snow processes when antecedent snow melt saturates the soils, and air temperature increases. In such cases, relatively low rainfall intensities may cause significant floods.

\section{Methodology}

Independent flood events were identified in the runoff data series. According to our understanding, two subsequent flood events are independent when they do not originate from the same synoptic situation. We assumed here that after a 7-day period, a completely different atmospheric situation takes place, since in Central Europe cyclonic situations (fronts, weather types, etc.) usually do not persist longer than 7 days on average. The flood type classification introduced by Merz and Blöschl (2003) and modified in Gaál et al. (2015) was used to classify each separate flood event into synoptic floods (originally long or short rain-induced floods), flash floods (no change in the original classification) and snowmelt floods (originally rain-on-snow floods or snowmelt floods). These three types were subsequently further grouped into two seasons, i.e., the summer and winter seasons, thereby separating the predominantly rainfall-fed (synoptic and flash) events and floods related to snowmelt.

Nine frequently used one-parametric copula families from several classes of copulas were fitted locally to the samples of the grouped data, namely from the Archimedean class (Clayton, Frank, Gumbel-Hougaard and Joe copula), the extremevalue class (Gumbel-Hougaard, Galambos, Hüsler-Reiss), the elliptical class (normal, Student $t$ ) and finally the Plackett copula. Their properties are summarized in Table 1. (The abbreviations of the copulas used throughout the paper are: cla $=$ Clayton, fra $=$ Frank, gal $=$ Galambos, gum $=$ Gumbel Hougaard, hus $=$ Hüsler-Reiss, joe $=$ Joe, nor $=$ Normal, pla $=$ Plackett, $t c o=t$ copula). The mathematical background is summarized in a number of papers and is not repeated here (e.g., Genest and Favre, 2007).

The parameters $\theta$ of the copulas were estimated by maximizing the so-called pseudo-likelihood function

$$
L(\theta)=\sum_{i} \log \left[c_{\theta}\left(U_{1, i}, U_{2, i}\right)\right],
$$

which, besides the copula density $c_{\theta}$, contains pseudoobservations $U_{j, i}(i=1, \ldots n, j=1,2)$, i.e., a transforma- 


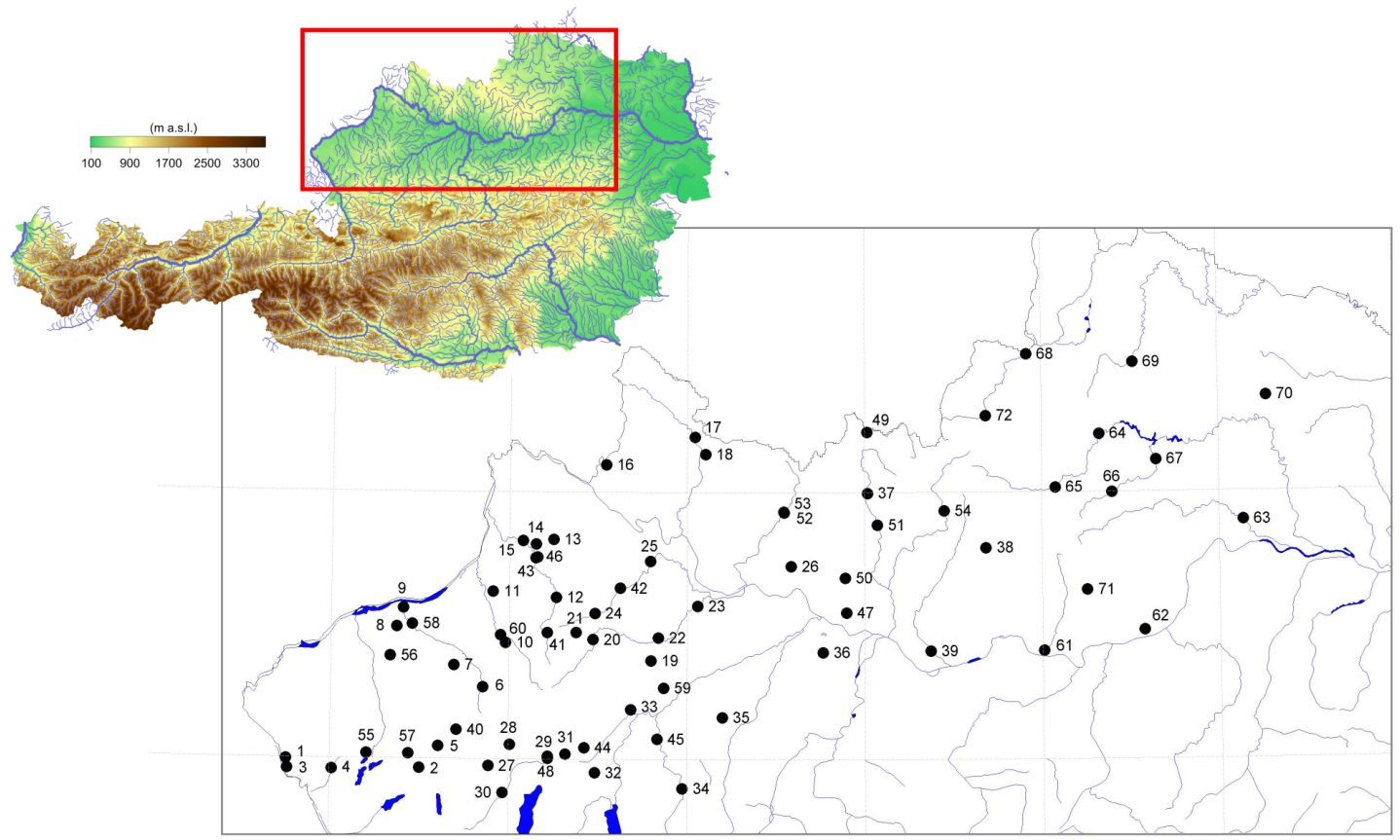

Figure 1. Geographical location of the 72 catchments selected.

Table 1. A summary of the 9 copula types fitted to the data.

\begin{tabular}{lcccc}
\hline $\begin{array}{l}\text { Copula } \\
\text { type }\end{array}$ & $\begin{array}{c}\text { Archimedean } \\
\text { copula }\end{array}$ & $\begin{array}{c}\text { Extreme } \\
\text { value copula }\end{array}$ & $\begin{array}{c}\text { Lower } \\
\text { tail dependence }\end{array}$ & $\begin{array}{c}\text { Upper } \\
\text { tail dependence }\end{array}$ \\
\hline Clayton & yes & no & yes & no \\
Frank & yes & no & no & no \\
Galambos & no & yes & no & yes \\
Gumbel-Hougaard & yes & yes & no & yes \\
Hüsler-Reiss & no & yes & no & yes \\
Joe & yes & no & no & yes \\
Normal (Gaussian) & no (elliptical) & no & no & no \\
Plackett & no & no & no & no \\
$t$ (Student) & no (elliptical) & no & yes & yes \\
\hline
\end{tabular}

tion of $n$ real observations of random variable $X_{j}$, by means of a corresponding empirical distribution function (sometimes referred to as the plotting position).

The goodness-of-fit was examined locally as well as analyzed in a regional scope. The goodness-of-fit of the parametric copulas under consideration was tested by a "blanket" test (Genest et al., 2009) with the Cramér-von Mises measure of distance

$S_{n}=\sum_{i=1}^{n}\left[C_{\theta}\left(U_{1, i}, U_{2, i}\right)-C_{n}\left(U_{1, i}, U_{2, i}\right)\right]^{2}$

between the parametric copula $C_{\theta}$ and the empirical copula defined by

$C_{n}\left(u_{1}, u_{2}\right)=\frac{1}{n} \sum_{i=1}^{n} 1\left(U_{1, i} \leq u_{1}\right) 1\left(U_{2, i} \leq u_{2}\right)$.
The probability distribution of the test statistic $S_{n}$, given that the null hypothesis $\left(H_{0}: C_{\theta}\right.$ fits well) holds, is unknown and needs to be bootstrapped. Consequently, the $p$-value is a percentage of how many simulations of the test statistic (under $H_{0}$ ) exceeds the estimator from the real observations.

\section{Results and discussion}

The $p$-values for the goodness-of-fit test of the nine copula types at the 72 catchments for the summer and winter floods are shown in Fig. 2. The copula types (each column represents a copula) are organized alphabetically, while the catchments are organized according to their original catchment IDs. The black color coding indicates $p \leq 0.05$, i.e., a rejection of the null hypothesis $H_{0}$, while the grey colors represent the results that $H_{0}$ cannot be rejected. Figure 3 summarizes 

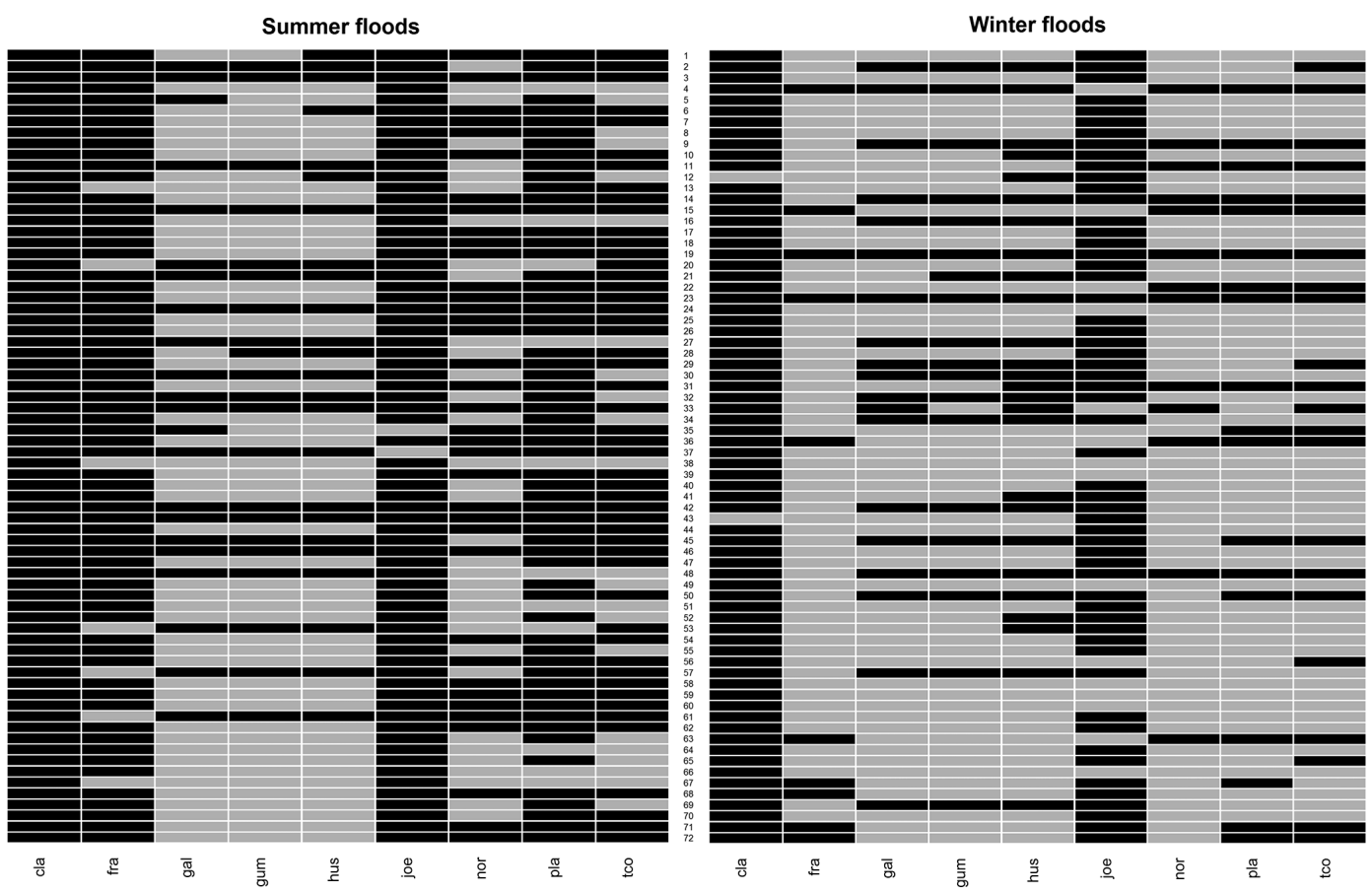

Figure 2. Matrix of $p$-values for the goodness-of-fit test of the nine copula types at 72 catchments for the summer (synoptic and flash) and winter (snowmelt) floods. The black color indicates $p \leq 0.05$, i.e., the rejection of the null hypothesis $H_{0}$, while the grey colors yield the fact that $H_{0}$ cannot be rejected.

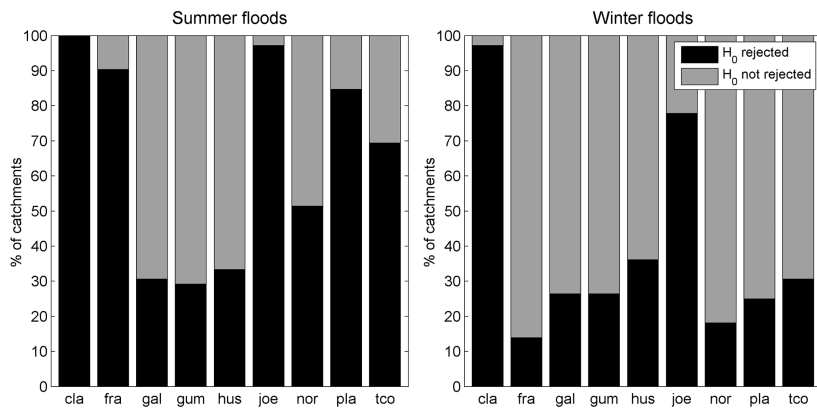

Figure 3. Results of the goodness-of-fit test of the given copula types for the summer and winter floods: per cent ratio of the catchments where the given copula is rejected or cannot be rejected.

the patterns from Fig. 2. It shows the ratio of the catchments where the given copula is rejected or cannot be rejected for the summer and winter floods.

It can be concluded that for the rainfall-fed floods, three extreme value copulas performed best in the region (the Galambos, Gumbel-Hougaard and Hüsler-Reiss copulas) followed by the normal copula. The other copulas cannot be regarded as regionally acceptable. The choice changed and broadened when the winter floods were analyzed: the best performer was the Frank copula, followed by the normal and Plackett copulas and the three extreme value models. The
Clayton and Joe copulas show an unacceptable performance for both seasons.

However, the number of events analyzed was different for each flood type. The numbers ranged from 123 to 399 (average 265), 18 to 150 (68) and 6 to 70 (24) for synoptic, snowmelt and flash floods, respectively. It was therefore further analyzed, if the different regional pattern of copula suitability in winter can only be attributed to the difference in the dependence structure itself (see Gaál et al., 2015, for a detailed discussion of the topic) or also to the fact that the number of winter events is lower compared to the summer floods (though larger than in many copula studies).

We illustrate the importance of considering the influence of the length of data series through two simple simulation experiments. In Fig. 4 the output from 20 randomly selected subsamples from the summer floods series is presented, where for all catchments the number of summer floods was set equal to the number of snowmelt floods. Figure 5 (left panel) shows the test results for a subset of catchments in which the number the winter floods was below the median (63 events and less). For comparison, the test results of the flash floods (which have the smallest number of events from all the flood types selected for this study) is also shown in the right panel in Fig. 5. Note that in some cases (indicated by N/A), the test could not be performed (i.e., copulas could not be fitted) due to the small data samples.

The preference for the choice of extremal copulas is still clearly visible from Fig. 4, however it is much less evident 

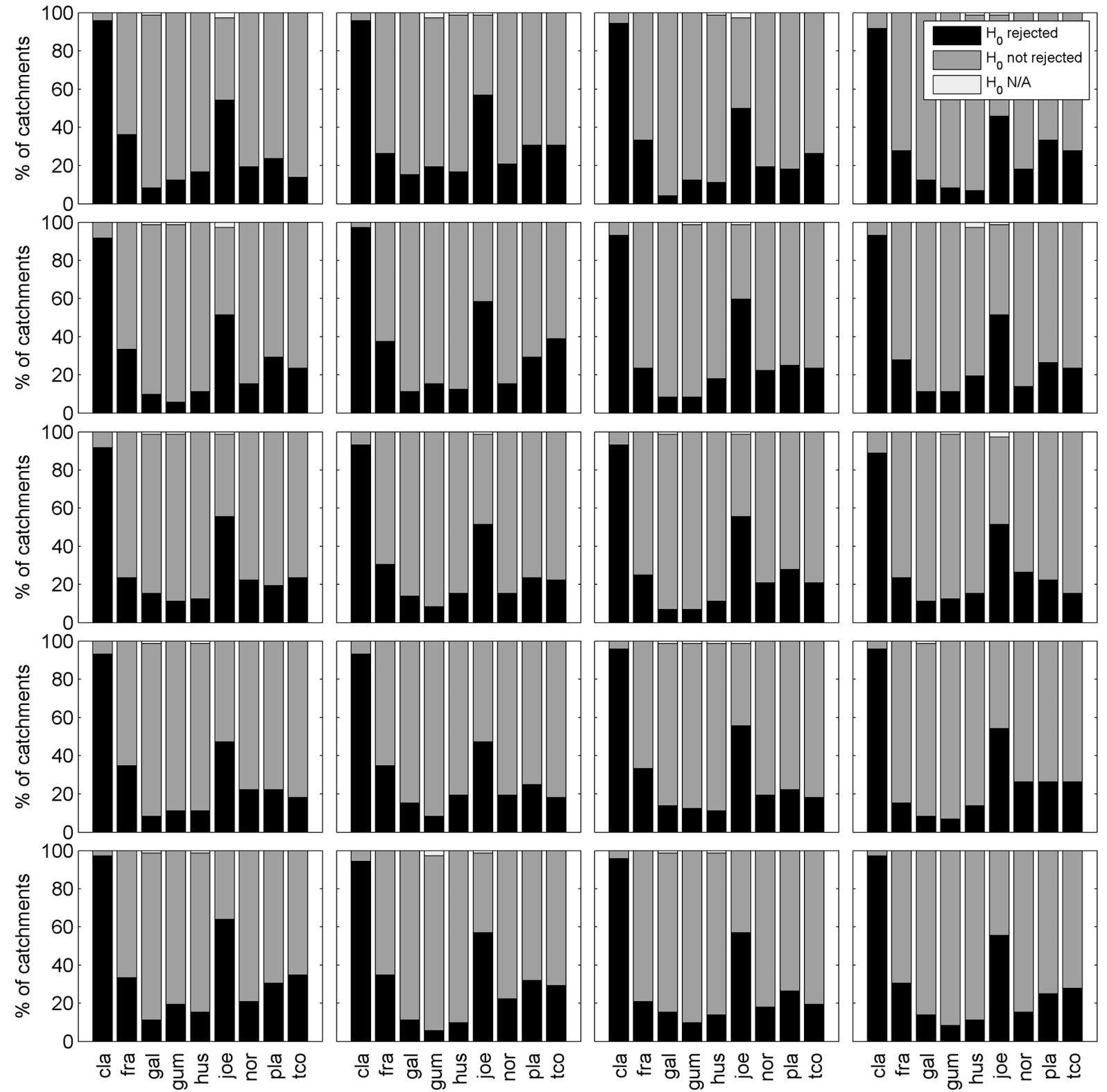

Figure 4. Results of the goodness-of-fit test of the given copula type for 20 randomly selected subsamples from the summer flood series, where for all catchments the number of summer floods was set equal to the number of snowmelt floods: per cent ratio of the catchments where the given copula is rejected or cannot be rejected or cannot be fitted due to a short data series (N/A).

and some of the patterns strongly resemble that of the winter floods (all events). The only clear tendency which remained is the high rejection rate of the Clayton and Joe copulas. The acceptance rate in Fig. 5 for the short winter flood series is higher for all types (but still more or less preserving the regional pattern), whereas for the very short flash flood series even the Clayton and Joe models approach the status of acceptability. These results indicate that acceptance of a copula model can be conditioned on processes but the length of the series and possibly also the homogeneity of the flood types within a series play an important role.
These were usually not taken into consideration in fitting studies. Despite numerous studies, as mentioned by Chowdhary et al. (2011), the use of copula-based multivariate distributions for hydrological designs still cannot be regarded as satisfactorily resolved. The crucial step in the multivariate modelling of flood characteristics by copulas seems to be the choice of the copula function which best fits the data (Favre et al., 2004). But, as shown above, the selection of the copula model that best fits the observed data is not a trivial issue even when only statistical aspects are taken into consideration. Several studies have been conducted regarding the 

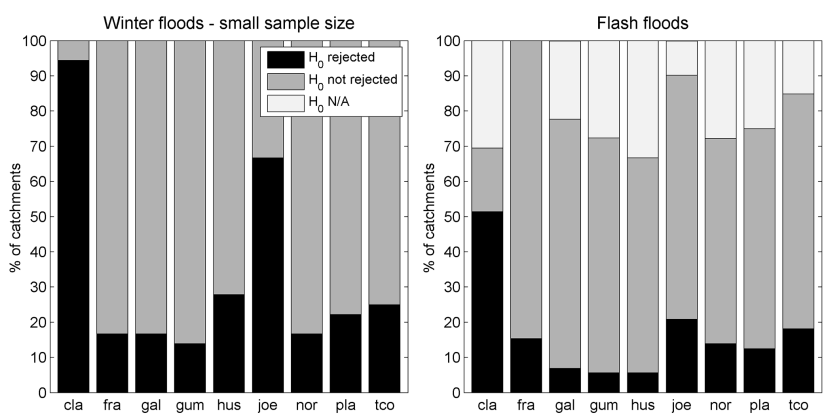

Figure 5. An analysis similar to that of presented in Fig. 3. Left panel: test results for a subset of catchments in which the number of the winter floods was below the median (63 events and less). Right panel: test results for the flash floods.

steps required to select a copula model (see, e.g., Genest and Favre, 2007). Our results support Favre et al. (2004), who emphasized that further work is needed to choose the best copulas capable of reproducing the dependence structure of multivariate hydrological variables.

\section{Conclusions}

Most of the work done so far does not relate to the hydrological adequacy of the copula selection, e.g., by directing the multivariate analysis toward the selection of certain types of models for specific runoff generation processes. The IID (= independent and identically distributed) requirement for the marginal distributions can also be seen as a weak point, especially when the extremes analyzed are not selected on the basis of the catchment and meteorological processes governing the flood generation.

Here the first issue was addressed in a regional context through a first step analysis by a rough differentiation of the flood types. It can be concluded that (i) modeling dependence by treating the flood processes separately in seasons is beneficial; (ii) the suitability patterns of acceptable copula types are distinguishably different for the seasons/processes considered, (iii) the Clayton and Joe copulas show an unacceptable performance for all the seasons/processes; (iv) the rejection rate of the other copula types depends on the season/flood type and also on the sample size (smaller samples allow for a broader selection of suitable models); (v) given that usually more than one statistically suitable dependence model exist, an uncertainty analysis of the design values in the engineering studies resulting from the choice of model is recommended; (vi) reducing uncertainty in the choice of model should be attempted by a deeper hydrological analysis of the dependence structure/model's suitability in specific hydrological environments or for a more specific distinction of the typical flood generation mechanisms. This will be done in a subsequent study.
Acknowledgements. We would like to thank the Austrian Academy of Sciences (International Strategy for Disaster Reduction Programme, IWHRE2008, 2008-2013), for the financial support. This research was also supported by the Slovak Research and Development Agency under Contract No. APVV 0496-10, by the Slovak Grant Agency VEGA under Project No. 1/0776/13 and by the IMPALA project (FP7-PEOPLE-2011-IEF-301953) of the Marie Curie Intra European Fellowship.

\section{References}

Chowdhary, H., Escobar, L. A., and Singh, V. P.: Identification of suitable copulas for bivariate frequency analysis of flood peak and flood volume data, Hydrol. Res., 42, 193-216, 2011.

De Michele, C., Salvadori, G., Canossi, M., Petaccia, A., and Rosso, R.: Bivariate statistical approach to check adequacy of dam spillway, J. Hydrol. Eng., 10, 50-57, 2005.

Favre, A.-C., El Adlouni, S., Perreault, L. Thiémonge, N., and Bobeé, B.: Multivariate hydrological frequency analysis using copulas, Water Resour. Res., 40, W01101, doi:10.1029/2003WR002456, 2004.

Gaál, L., Szolgay, J., Kohnová, S., Parajka, J., Merz, R., Viglione, A., and Blöschl, G.: Flood timescales: Understanding the interplay of climate and catchment processes through comparative hydrology, Water Resour. Res., 48, W04511, doi:10.1029/2011WR011509, 2012.

Gaál, L., Szolgay, J., Kohnová, S., Hlavčová, K., Parajka, J., Viglione, A., Merz, R., and Blöschl, G.: Dependence between flood peaks and volumes - A case study on climate and hydrological controls, Hydrol. Sci. J., 60, doi:10.1080/02626667.2014.951361, in press, 2015.

Genest, C. and Favre, A.-C.: Everything you always wanted to know about copula modeling but were afraid to ask, J. Hydrol. Eng., 12, 347-368, 2007.

Genest, C., Rémillard, B., and Beaudoin, D.: Goodness-of-fit tests for copulas: A review and a power study, Insurance: Mathematics and Economics, 44, 199-213, 2009.

Goel, N. K., Seth, S. M., and Chandra, S.: Multivariate modeling of flood flows. ASCE, J. Hydraul. Eng., 124, 146-155, 1998.

Merz, R. and Blöschl, G.: A process typology of regional floods, Water Resour. Res., 39, 1340, doi:10.1029/2002WR001952, 2003.

Requena, A. I., Mediero, L., and Garrote, L.: A bivariate return period based on copulas for hydrologic dam design: accounting for reservoir routing in risk estimation, Hydrol. Earth Syst. Sci., 17, 3023-3038, doi:10.5194/hess-17-3023-2013, 2013.

Shiau, J. T.: Return period of bivariate distributed extreme hydrological events, Stoch. Environ. Res. Risk Assess., 17, 42-57, 2003.

Yue, S., Ouarda, T. B. M. J., Bobeé, B., Legendre, P., and Bruneau, P.: Approach for describing statistical properties of flood hydrograph, J. Hydrol. Eng., 7, 147-53, 2002. 